\title{
ANALISIS PENGARUH TEMPERATUR, WAKTU, DAN KUAT ARUS PROSES ELEKTROPLATING TERHADAP KUAT TARIK, KUAT TEKUK DAN KEKERASAN PADA BAJA KARBON RENDAH
}

\author{
Abdul Rasyad ${ }^{1}$ dan Budi Arto ${ }^{2}$ \\ ${ }^{1} \mathrm{PT}$. Utama Raya Motor Industri, Tangerang \\ Jl. Raya Pasar Kemis, km 05, Jati uwung, Tangerang, Banten \\ ${ }^{2}$ Prodi Teknik Mesin, Fakultas Teknik, UKI, Jakarta \\ Jl. Mayjen. Sutoyo no. 2 Cawang Jakartaa \\ 1Email: abd.rasyad@gmail.com, ${ }^{2}$ budidamaz@gmail.com
}

\begin{abstract}
The researcher has analyzed the effect of temperature, time, and electrical current of electroplating process on tensile strength, bending strength and hardness of low carbon steel. The aim of this research is to know the effect of temperature, time, and electrical current as the parameters of electroplating process on tensile strength, bending strength and hardness of low carbon steel plate material treated using nickel and chrome coating materials. Coating process was operated with variations in temperature of $50^{\circ} \mathrm{C}, 55^{\circ} \mathrm{C}, 60^{\circ} \mathrm{C}$; coating time of 5 minutes, 10 minutes, 15 minutes; and electrical currents of 4 A, 5 A, 6 A. Tensile strength and buckling tests were conducted using a versatile test machine (Universal Testing Machine) and hardness test with Vickers method. The tensile strength test results show that the higher temperature, time and electrical current during the coating process, give the greater of tensile strength value (from $307 \mathrm{~N} /$ $m^{2}$ to $376 \mathrm{~N} / \mathrm{m}^{2}$ ), as well as buckling strength testing. The smaller of buckling strength value from $11.5 \mathrm{~kg} / \mathrm{m}^{2}$ to $7.5 \mathrm{~kg} / \mathrm{mm}^{2}$. Hardness test results indicate a significant increase in the value of hardness in the temperature variation, time, and the electrical current coating, where the hardness value is from $89.3 \mathrm{HV}$ to $100 \mathrm{HV}$.
\end{abstract}

Keywords: electroplating process, tensile strength, bending strength, hardness.

\section{LATAR BELAKANG}

Perkembangan industri dan kemajuan ilmu pengetahuan serta teknologi memungkinkan manusia untuk memenuhi berbagai macam kebutuhannya. Misalnya saja kebutuhan akan barang berbahan dasar logam. IImu pengetahuan tentang logam memungkinkan berbagai barang logam dapat dibuat, dibentuk, dicetak sesuai bentuk yang dikehendaki. Dengan demikian ilmu pengetahuan dan tekhnologi merubah material menjadi barang yang harus tampil indah dan menarik, terutama barang logam untuk peralatan perkantoran atau rumah tangga, permesinan dan assesoris automotif. Selain indah dan menarik material tersebut juga harus kuat, dan tahan lama.Faktor ekonomis, kekuatan struktural, keawetan dan agar terlindungi dari korosi adalah alasan adanya finishing [1]. Finishing bisa berupa pengecatan atau elektroplating.

Electroplating merupakan salah satu proses pelapisan yang memanfaatkan prinsip elektrokimia. Sehingga untuk mendapatkan pengetahuan yang lebih mendalam dari formulasi dan komposisi dari larutan, maka pengetahuan tentang ilmu kimia sangat dibutuhkan. Teknologi pelapisan juga memakai zat adiktif tetapi hingga saat ini zat adiktif yang ada sering kali dirahasiakan, sehingga informasinya terbatas dan hanya tersedia dalam bentuk patennya.Dalam electroplating arus dan distribusinya merupakan parameter yag sangat penting bila dibandingkan dengan potensial, kerena biasa digunakan sebagai pengendali dari hasil pelapisan. [2,3]. 
Yang termasuk dalam kelompok electroplating dekoratif dan protektif disini adalah nikel dan kromium. dasar pengelompokan nikel dan kromium menjadi satu topik pembahasan tersendiri dan biasanya kedua jenis logam tersebut dipakai plating bersama-sama pada satu benda kerja, tetapi pada masyarakat umum dikenal dengan nama "plating krom/ verkrum ". Kegunaan dari plating nikel, dan kromium adalah sebagai fungsi dekoratif atau protektif.[4]

Plating nikel dan krom memiliki kegunaan yang besar dibidang teknik karena memiliki sifat fisik yang menguntungkan, seperti tahan aus ,tahan korosi dan biasa dipakai dalam elektroforming.[5] Sedangkan kromium memiliki sifat utama yang sangat keras, getas dan mengkilat. Sebagian besar dalam aplikasinya lapisan nikel (nikel plating) sedangkan krom adalah sebagai elektroplating standart yang sering digunakan orang sekalipun kedua unsur ini memiliki sifat kimia dan sifat fisik yang berbeda.

Pada penelitian ini dimana baja karbon rendahakan dilapisi nikel dan krom dengan cara electroplating pada kondisi parameter prosespelapisan yaitu waktu, temperatur dan kuat arus listrik. Karakterisasi untuk ujlati kekuatan tarik, dan kekuatan tekuk menggunakan a Universal Testing Mesin (UTM), dan untuk uji kekerasan dengan menggunakan metode Vickers.

Secara umum penelitian ini diharapkan dapat menunjang program pemerintah dalam pengembangan industri kecil dan menengah, khususnya komponen alat kantor dan rumah tangga. Secara khusus penelitian ini bertujuan untuk mempelajari karakteristik dari material karbon rendah terhadap pengaruh waktu, temperatur dan kuat arus listrik pelapisan dengan nikel krom.

\section{TINJAUAN PUSTAKA}

Treatment bahan, baik untuk bahan konduktor maupun non konduktor. Selain sifat dekoratif, keuntungan teknik surface treatment juga bisa meningkatkan kekerasan, ketahanan aus, dan ketahanan korosi.

\section{Baja Karbon}

Baja karbon rendah merupakan salah satu jenis logam yang banyak diaplikasikanpada dunia industri terkait dengan penanganan asam, basa, ataupun garam. Namun jenis logam ini memiliki keterbatasan dalam hal ketahanan korosi.Asam klorida adalah salah satu jenis asam yangsangat agresif dan korosif [5].Oleh karena itu diperlukan upaya untuk memperbaiki performa kerja dari baja karbon rendah agar ketahanan korosinya lebih baik dan dapat diaplikasikan lebih optimal dan luas lagi. Salah satu cara untuk meningkatkan ketahanan korosi dari baja karbon rendah yaitu dengan memberikan lapisan proteksi pada permukaan baja karbon rendah dengan paduan logam yang memiliki ketahanan tinggi terhadap lingkungan korosif.[6][7] Paduan logam berbasis Nikel umumnya banyak dipakai sebagai material pelapis, yaitu paduan nikel - krom yang telah diketahui sebelumnya memiliki banyak kelebihan diantaranya sifat mekanik yang baik dan dapat meningkatkan ketahanan panas[8].

Peneliti terdahulu menunjukkan bahwa pelapisan dengan krom telah meningkatkan nilai kekerasan, menurunkan laju korosi dan menurunkan nilai keausan spesifik pada baja karbon rendah (AISI 1008). Nilai kekerasan akan semakin meningkat dengan bertambahnya waktu proses pelapisan krom, dimana waktu 60 menit nilai kekerasan tertinggi yaitu $562 \mathrm{VHN}$, dan laju korosi mengalami penurunan dengan bertambahnya waktu proses pelapisan krom, laju korosi terendah pada waktu 60 menit yaitu 0,989 mpy[9]. Peningkatan sifat fisis dan mekanis permukaan material, bisa dilakukan dengan cara mechanical treatment, termo kimia, konversi atau cara coating. Teknik lapis listrik nickel, hard chrome dan nickel-hard-chrome merupakan salah satu teknik surface treatment.[10] 
Pelapisan (Elektroplating )

Pelapisan adalah suatu proses Pada katoda, pembentukan lapisan nikel

pengendapan logam pada permukaan suatu logam atau non logam (benda kerja), secara eletrolisis(Gambar 1). Endapan yang terjadi bersifat adhesif terhadap logam dasar, yang bertujuan membentuk permukaan dengan sifat dan dimensi yang berbeda dengan logam dasarnya. Dalam proses electroplating ini lapisan fasa padat (biasanya logam murni atau paduan) diendapkan atau dilapis secara elektrik dari sebuah larutan yang dengan proses yang dinamakan "elektrodeposisi", elektrodeposisi terbentuk selama proses elektrolisis terjadi dalam larutan yang mengandung garam-garam logam atau ion-ion logam yang dikenal sebagai "elektrolit". Arus masuk dan keluar elektrolit melalui dua elektroda penghubung yang dinamakan anoda dan katoda. Arus dalam larutan terdiri dari dua macam, yaitu aliran bermuatan positif dari anoda ke katoda atau juga aliran dari elektron dengan arah sebaliknya atau negatif. Kedua aliran ini umumnya mempunyai harga muatan yang sama atau ekivalen. Selama elektrolisasi seluruh larutan yang mengandung ion membawa arus, tergantung pada konsentrasi dan mobilitas yang terjadi pada katoda, yang pada akhirnya mengarah pada pembentukan (yaitu sebuah kelebihan ) dari kation positif pada katoda, dimana dari kebanyakan dari ion-ion yang bermuatan positif akan berkurang. Anion dengan potensial bermuatan negative pada anoda akan teroksidasi.

Pelapisan suatu logam secara elektrolisa ini melalui penggunaan arus listrik searah (direct current atau DC) dan larutan kimia (elektrolit) yang berfungsi sebagai media penyuplai ion-ion logam membentuk endapan (lapisan) logam pada elektroda katoda.Perpindahan ion logam dengan bantuan arus listrik melalui larutan elektrolit sehingga ion logam mengendap pada benda padat yang akan dilapisi, Ion logam diperoleh dari elektrolit maupun berasal dari pelarutan anoda logam didalam elektrolit. Pengendapan terjadi pada benda kerja yang berlaku sebagai katoda. Reaksi kimia yang terjadi pada proses pelapisan seperti yang terlihat pada gambar 1. dapat dijelaskan sebagai berikut :

$$
\mathrm{Ni}^{2+}{ }_{(\mathrm{aq})}+2 \mathrm{e}^{-} \rightarrow \mathrm{Ni}_{(\mathrm{s})}
$$

Pembentukan gas hidrogen,

$2 \mathrm{H}^{+}{ }_{(\mathrm{aq})}+2 \mathrm{e}-\mathrm{H} \rightarrow \mathrm{H}_{2}(\mathrm{~g})$

reduksi oksigen terlarut,

$1 / 2 \mathrm{O}_{2(\mathrm{~g})}+2 \mathrm{H}^{+} \rightarrow \mathrm{H}_{2} \mathrm{O}_{(\mathrm{l}) .}$

Pada anoda, pembentukan gas oksigen

$\mathrm{H}_{2} \mathrm{O}(\mathrm{l}) \rightarrow 4 \mathrm{H}^{+}(\mathrm{aq})+\mathrm{O}_{2(\mathrm{~g})}+4 \mathrm{e}^{-}$,

oksidasi gas hidrogen $\mathrm{H}_{2}(\mathrm{~g}) \rightarrow 2 \mathrm{H}^{+}{ }_{(\mathrm{aq})}+2 \mathrm{e}^{-}$

Untuk menghitung berat pelapisan secara teori digunakan Hukum Faraday yaitu massa zat yang terbentuk selama elektroplating berbanding lurus dengan jumlah arus yang mengalir. Rumus yang digunakan secara teori,

$\mathrm{W}=$ I.t.e $/ 96500$

Dimana, W adalah berat pelapisan (gr), I adalah kuat arus (A), t adalah waktu (detik), e adalah berat ekivalen (MA/valensi). Dari rumus tersebut, ketebalan endapan pelapis dapat diperoleh dengan perhitungan :

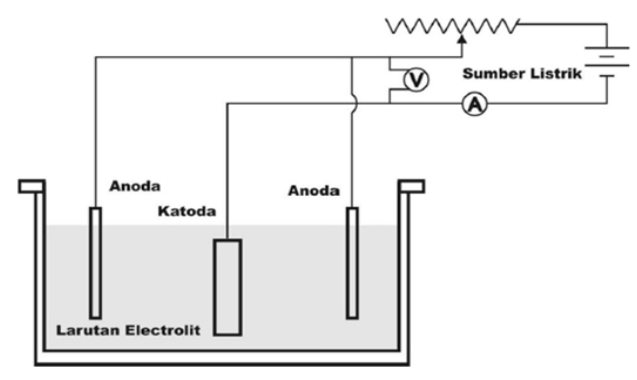

Gambar 1. Rangkaian Proses Pelapisan 


$$
\text { Density }=\frac{\text { Berat endapan }}{\text { Volume }}\left(\frac{\mathrm{gr}}{\mathrm{cm}^{3}}\right)
$$

Dengan mengukur langsung permukaan benda kerja / bahan uji (katoda), ketebalan dapat ditentukan sebagai berikut:

$$
\text { Ketebalan }(\mathrm{cm})=\frac{\text { Volume }\left(\mathrm{cm}^{3}\right)}{\text { Luas permukaan }\left(\mathrm{cm}^{3}\right)}
$$

Besarnya pengujian tarik dapat dihitung dengan persamaan diuraikan sebagai berikut ini :

$$
\begin{aligned}
\varepsilon & =\frac{\Delta L}{L_{0}} \\
& =\frac{L_{0}-L_{1}}{L_{0}} \times 100 \% \\
\sigma_{U} & =\frac{P_{\text {Mas }}}{A_{0}} \\
E & =\frac{\sigma}{\epsilon}
\end{aligned}
$$

Dimana adalah kekuatan tarik

maksimum $\left(\mathrm{N} / \mathrm{mm}^{2}\right), \quad \mathrm{P}_{\mathrm{Max}}$ adalah gaya maksimum $(\mathrm{N})$, $\mathrm{E}$ adalah modulus elastisitas $\left(\mathrm{kg} / \mathrm{mm}^{2}\right), \varepsilon$ adalah regangan $(\%), \Delta L$ adalah perpanjangan atau deformasi $(\mathrm{mm}), \mathrm{L}_{0}$ adalah panjangan mula - mula $(\mathrm{mm}), \mathrm{L}_{1}$ adalah panjangan setelah patah $(\mathrm{mm})$.

Besarnya nilai kekerasan vickers dapat dihitung dengan rumus :

$$
\begin{gathered}
H V=\frac{2 F \operatorname{Sin} \frac{\alpha}{2}}{d^{2}} \\
H V=18544 \frac{F}{d^{2}}
\end{gathered}
$$

Dimana HV adalah Hardness Vickers $\left(\mathrm{g} / \mu \mathrm{m}^{2}\right), \quad F$ adalah beban dalam gram $(\mathrm{g}), \quad d$ adalah rata-rata dari kedua diagonal, $d_{1}$ dan $d_{2}$ dalam $\mu \mathrm{m}$.

Plating termasuk salah satu cara menanggulangi korosi pada logam dan juga berfungsi sebagai ketahanan bahan. Disamping itu plating juga memberikan nilai estetika pada logam yang dilapisi, yaitu warna dan tekstur tertentu, serta untuk mengurangi tahanan kontak serta meningkatkan konduktivitas permukaan atau daya pantul. Sebelum dilakukan pelapisan pada bahan dasar, permukaan logam harus disiapkan untuk menerima adanya lapisan. Persiapan ini bertujuan untuk meningkatkan daya ikat antara lapisan dengan bahan yang dilapisi. meng. Proses ini meliputi abrasi mekanik yang dilakukan untuk jenis inert, pencucian untuk menghilangkan lemak, minyak dan debu agar lebih bersih, dapat digunakan larutan organik dan larutan alkali untuk menghilangkan oksidasinya. Secara prinsip proses pelapisan mencakup empat hal, yaitu pembersihan, pembilasan, pelapisan dan proteksi setelah pelapisan. Keempat hal ini dapat dilakukan secara manual atau bisa juga menggunakan tingkat otomatisasi yang lebih tinggi lagi.

Parameter-parameter yang berpengaruh ) terhadap kualitas pelapisan nikel krom, diantaranya adalah konsentrasi larutan, rapat arus, temperatur dan waktu pelapisan[5].

\section{Komposisi larutan}

Elektrolit adalah zat-zat yang dapat menghantarkan arus listrik. Pada dasarnya elektrolit yang dipergunakan dalam bentuk larutan asam/basa dicampur dengan air murni. Air murni yang dimaksudkan adalah air yang tidak mengandung zat yang dapat merubah sifat elektrolit.dengan tujuan antara lain:

a. Unsur logam yang dideposisikan (dilarutkan)

b. Membentuk kompleks dengan ion logam deposisinya

c. Menyediakan sarana hantaran listrik

d. Stabilisasi larutan

e. Stabilisasi tingkat keasaman $(\mathrm{pH})$

f. Mengubah/mengatur bentuk fisik deposit

g. Membantu larutan anoda

h. Mengatur sifat-sifat lain larutan/depositnya Larutan elektrolit yaitu zat-zat yang dilarutkan dalam air murni yang dapat menjembatani partikel-partikel bermigrasi dari anoda ke katoda. Konsentrasi ini akan berkaitan dengan nilai $\mathrm{pH}$ dari larutan. Pada larutan elektrolit nikel mempunyai batas-batas $\mathrm{pH}$ yang diijinkan agar proses tersebut berlangsung baik, berkisar antara $2-4,5$ [11]. Jika nilai $\mathrm{pH}$ melebihi dari nilai yang dijinkan maka akan terjadi sumuran 
pada permukaan produk dan lapisan nikel kasar pada permukaan benda yang dilapisi.

Dalam proses pelapisan nikel temperatur elektrolit juga sangat menetukan hasil pelapisan temperatur diatur sesuai dengan ketentuan yang ada, untuk meratakan distribusi ion nikel agar supaya ketebalan yang diperoleh sama maka dalam proses elektroplating dibutuhkan pengaduk dengan mengunakan udara dengan cara dihembuskan melalui kompresor kedalam elektrolit, bisa juga secara mekanik yaitu diaduk langsung dengan menggunakan pengaduk.

Arus yang digunakan juga harus disesuaikan dengan luasan permukaan yang dilapisi dimana semakin luas permukaan yang dilapisi maka arus yang digunakan juga harus semakain besar, tapi bukan bearti boleh melebihi ketentuan yang sudah ada.

\section{Keasaman $(p H)$}

Keasaman $(\mathrm{pH}) 2$ - 4,5 merupakan salah satu faktor yang penting dalam proses elektroplating maka dari itu dalam prosesnya $\mathrm{pH}$ ini harus dipertahankan, untuk mempertahankan ini maka digunakan asam borak.

\section{Rapat Arus}

Rapat arus adalah harga yang menyatakan jumlah arus listrik yang mengalir persatuan luas permukaan elektroda.Terbagi dalam dua macam rapat arus anoda dan rapat arus katoda. Pada proses lapis listrik rapat arus yang diperhitungkan adalah rapat arus katoda, yaitu banyaknya arus listrik yang diperlukan untuk mendapatkan atom-atom logam pada tiap satuan luas permukaan benda kerja yang akan dilapis. Untuk proses elektroplating ini faktor rapat arus memegang peranan sangat penting, karena akan mempengaruhi efisiensi pelapisan, reaksi reduksi oksidasi dan difusi dari hasil pelapisan pada permukaan benda yang dilapisi.

\section{Temperatur dan waktu pelapisan}

Temperatur terlalu rendah dan rapat arus yang cukup optimum akan mengakibatkan hasil pelapisan menjadi kasar dan kusam, tetapi jika temperatur tinggi dengan rapat arus yang optimum maka hasil pelapisan menjadi tidak merata. Waktu pelapisan akan mempengaruhi terhadap kuantitas dari hasil pelapisan yang terjadi dipermukaan produk yang dilapis.

\section{METODE PENELITIAN}

Bahan baja karbon rendah (Gambar 1.) diperoleh dari PT.URMI, dan sebagian besar kegiatan penelitian, yaitu proses pelapisan pada baja karbon dilakukan di laboratorium PT. Utama Raya Motor Industri. Pengujian tarik yang dilakukan mengacu pada standart ASTM E8/E8M-09.

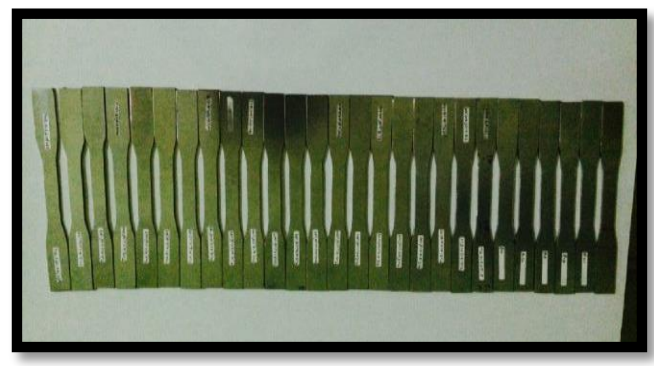

Gambar 1. Material Plat Baja Karbon

Keterangan:

- Plat tebal $0,2 \mathrm{Cm}$, lebar $3 \mathrm{Cm}$,

- Panjang 2,6 Cm.

- Larutan yang digunakan : Nikel Sulfate, Nikel Chlorida, Stating Solution, SB Wetting Agent, Nikel Round, Chrome Trioxide, Chrome zmitel.

Peralatan yang dipakai ditunjukkan pada Gambar 2

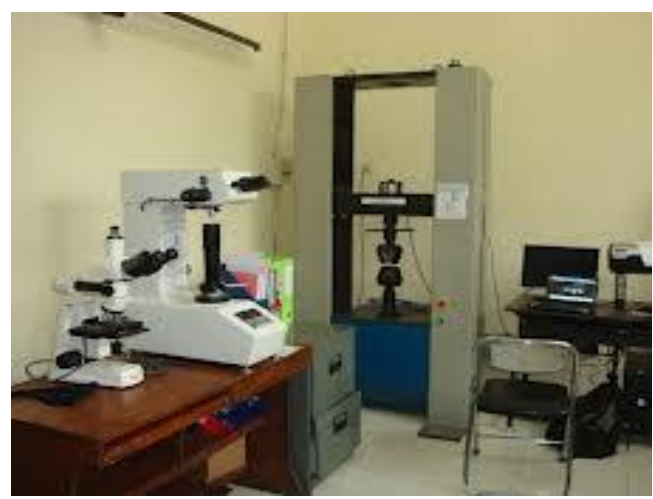

(a)

(b)

Gambar 2. Alat uji (a) kekerasan dan (b) tarik 


\section{Langkah Pelapisan}

Adapun langkah - langkah dalam melakukan proses pelapisan adalah (a) Menyiapkan alat dan bahan yang akan digunakan selama pelapisan, (b) Memasang semua alat untuk proses pelapisan, (c) Mempersiapkan larutan, kemudian larutan tersebut dipanaskan sampai temperatur $50^{\circ} \mathrm{C}, 55^{\circ} \mathrm{C}, 60^{\circ} \mathrm{C}$ untuk pelapisan nikel (d). Mempersiapkan benda kerja yang akan dilapisi dan telah dibersihkan dengan larutan pembersih, (e) Proses pelapisan pertama, benda kerja yang akan dilapisi diletakan pada kutub negatif dan plat nikel pada kutub positif, (f) Benda kerja dicelupkan kemudian stop kontak dihidupkan, (g) Pelapisan dilakukan dengan waktu sesuai dengan ketebalan lapisan yang diinginkan, waktu pencelupan yaitu 5 menit, 10 menit, 15 menit dengan dilakukan tiga kali pengulangan, (h) Pembilasan dilakukan pada benda kerja sebelum dilakukan proses kedua, (i) Proses pelapisan kedua, benda kerja dicelupkan ke dalam larutan krom dengan tegangan 5 Volt dan waktu pencelupan sesuai dengan variasi waktu, (j) Pembersihan benda kerja sebelum dilakukan pengujian iluminasi cahaya dan pengukuran ketebalan, (k) pengujian iluminasi cahaya dilakukan pada permukaan benda kerja yang datar dan yang terlihat paling cerah serta mengukur ketebalannya

Setelah dilakukan proses pelapisan dengan variasi parameter temperatur, waktu, dan A didapatkan bentuk kecerahan yang berbeda beda, kemudian dilakukan pengukuran terhadapnya berupa pengukuran ketebalan lapisan terhadap setiap sampel uji. Pada setiap sampel terdapat 4 buah titik dan diambil ratarata nilai ketebalan lapisannya dari setiap sampel.

\section{HASIL DAN PEMBAHASAN Analisis uji kekuatan tarik}

Dari hasil pengujian kekuatan tarik terhadap temperatur dan variasi kuat arus dapat dilihat pada gambar $3 a$ dan $3 b$, di bawah ini.

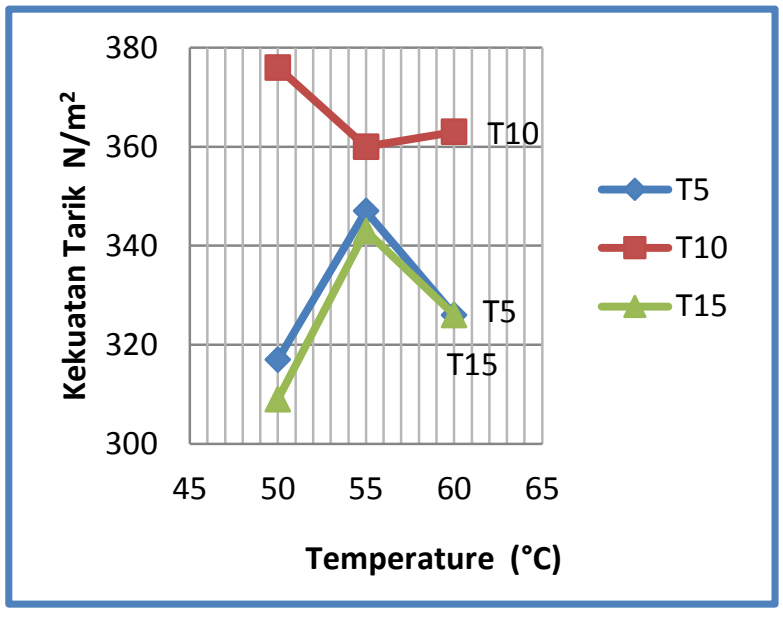

(a)

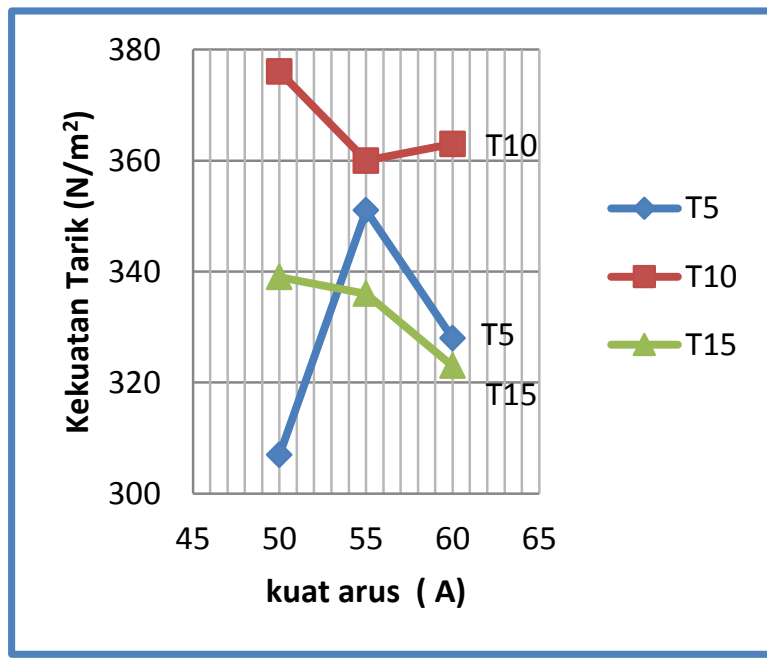

(b)

Gambar 3. Grafik kekuatan tarik terhadap (a) temperature dan (b) kuat arus, dengan variasi waktu proses elektroplating $\mathrm{Ni}-\mathrm{Cr}$.

Gambar 3a, menunjukkan bahwa dengan waktu proses elektroplating 5 menit, nilai kekuatan tarik mencapai titik tertinggi $348 \mathrm{~N} / \mathrm{m}^{2}$ pada temperatur $55^{\circ} \mathrm{C}$. Ternyata pada waktu proses selama 10 menit memiliki kekuatan tarik tertinggi $377 \mathrm{~N} / \mathrm{m}^{2}$ pada temperatur $50^{\circ} \mathrm{C}$ dan nilai kekuatan tarik terendah $305 \mathrm{~N} / \mathrm{m}^{2}$ pada temperatur $50^{\circ} \mathrm{C}$ dengan waktu 15 menit. Pada 
saat dilakukan percobaan pelapisan nikel krom dengan A dinaikkan menjadi $6 \mathrm{~A}$, dengan variasi waktu 5 menit, 10 menit, 15 menit dan variasi temperatur $50^{\circ} \mathrm{C}, 55^{\circ} \mathrm{C}, 60^{\circ} \mathrm{C}$ didapat hasil kekuatan tarik dari $351 \mathrm{~N} / \mathrm{m}^{2}$ pada temperatur $50^{\circ} \mathrm{C}$ dan mengalami kenaikan menjadi 351 $\mathrm{N} / \mathrm{m}^{2}$ pada temperatur $55^{\circ} \mathrm{C}$.

Ketika kita naikkan temperatur yang lebih tinggi yaitu $60^{\circ} \mathrm{C}$ justru kekuatan tariknya malah turun menjadi $328 \mathrm{~N} / \mathrm{m}^{2}$ dan pada saat waktu dinaikkan menjadi 10 menit maka kekuatan tarik nya pada sampel mengalami kenaikan yang signifikan yaitu dari 345..pada temperatue $50^{\circ} \mathrm{C}$ dan $55^{\circ} \mathrm{C}$ derajat menjadi 364 $\mathrm{N} / \mathrm{m}^{2}$ pada temperatur $60^{\circ} \mathrm{C}$. Sedangkan ketika dinaikkan lagi waktunya menjadi 15 menit didapatkan kekuatan tarik $339 \mathrm{~N} / \mathrm{m}^{2}$ pada temperatur $50^{\circ} \mathrm{C}$ lebih tinggi dari pada kekutan tarik ketik pada temperatur $55^{\circ} \mathrm{C}$ dan $60^{\circ} \mathrm{C}$ yaitu $336 \mathrm{~N} / \mathrm{m}^{2}$ dan $323 \mathrm{~N} / \mathrm{m}^{2}$ dapat disimpulkan bahwa semakin lama waktu celup tidak selalu dikuti kenaikan temperatur untuk medapatkan kekuatan tarik yang lebih tinggi pada kuat arus yang konstan.

Pangaruh temperatur terhadap nilai kekuatan tarik setelah proses pelapisan nikel krom, gambar $3 a$ dan $3 b$ di atas menunjukkan bahwa temperatur operasional semakin tinggi, maka nilai kekuatan tariknya relatif meningkat. Tetapi dalam satu kondisi temperatur operasional, peningkatan waktu pelapisan terdapat ketidakteraturan kenaikan nilai kekuatan tarik. Dari diagram menunjukkan bahwa nilai kekuatan tarik permukaan lapisan nikel kroml lebih dominan dipengaruhi oleh temperatur operasional dari pada oleh lamanya waktu pelapisan. Karena semakin besar nilai kuat arus listrik yang digunakan, maka akan menyebabkan elektron lebih reaktif (lebih mudah bergerak), Hal ini juga akan menyebabkan porsi akumulasi pergerakan elektron dan transfer material pada kedua elektroda juga akan semakin besar.Dari penjelasan tersebut di atas, maka Indikasi adanya Pengaruh kuat arus listrik dan waktu proses terhadap ketebalan lapisan yang terbentuk ditandai dengan terjadinya perubahan nilai ketebalan lapisan jika nilai dari kedua variabel bebas dibuat bervariasi. Pola pengaruh yang teramati adalah berbanding lurus.

\section{Analisis pengujian kekuatan tekuk}

Hasil uji kuat tekuk dari bahan dasar asli atau belum dilapisi adalah $10,5 \mathrm{~kg} / \mathrm{mm}^{2}$. Pada gambar 4.a, memperlihatkan grafik hasil uji tekuk pada kondisi temperatur tetap $60{ }^{\circ} \mathrm{C}$, dan variasi kondisi, untuk grafik 4.a)E dimana sampel dilapisi nikel dan chrome, waktu celup 10 menit dan kuat arus listrik 6 A nilai kekuatan tekuknya adalah $11,25 \mathrm{~kg} / \mathrm{mm}^{2}$, gambar $\left.4 . \mathrm{a}\right) \mathrm{F}$ sampel dilapisi nikel dan chrome, waktu celup 15 menit dan kuat arus listrik 6 A nilai kekuatan tekuk $10,5 \mathrm{~kg} / \mathrm{mm}^{2}$ dan gambar 4.a)G sampel nikel dengan waktu celup 5 menit serta kuat arus listrik 6 A, nilai kekuatan tekuknya turun menjadi $10 \mathrm{~kg} / \mathrm{mm}^{2}$.

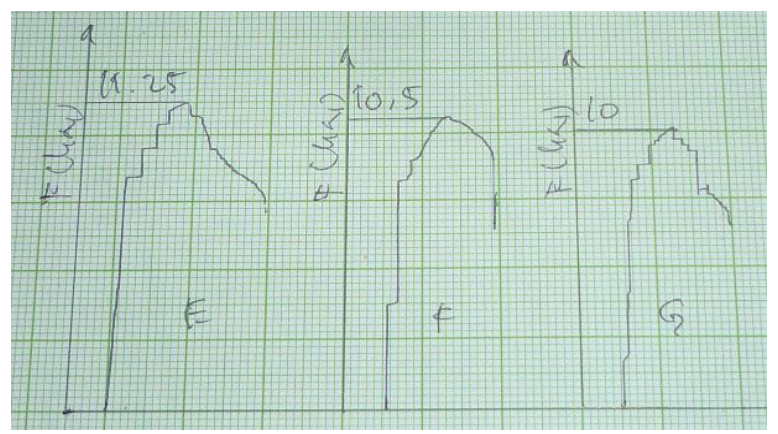

Gambar 4.a Grafik hasil uji tekuk pada temperatur tetap $60^{\circ} \mathrm{C}$, dan kondisi waktu elektroplating tetap 15 menit serta variasi kuat arus E). 4 A, F). $5 \mathrm{~A}, \mathrm{G}) .6 \mathrm{~A}$.

Dari Gambar 4a di atas mempunyai perbedaan hasil uji kekuatan tekuk yang signifikan, dimana perbedaannya sekitar $12,5 \%$. Hal ini disebabkan karena ada perbedaan kuat arus listrik saat proses pelapisan, dimana kuat arus listrik dapat mempengaruhi ketebalan lapisan yang terbentuk. Dengan ketebalan lapisan yang besar pada sampel akan 
menambah tahanan dari kekuatan tekuk atau bending saat diuji.

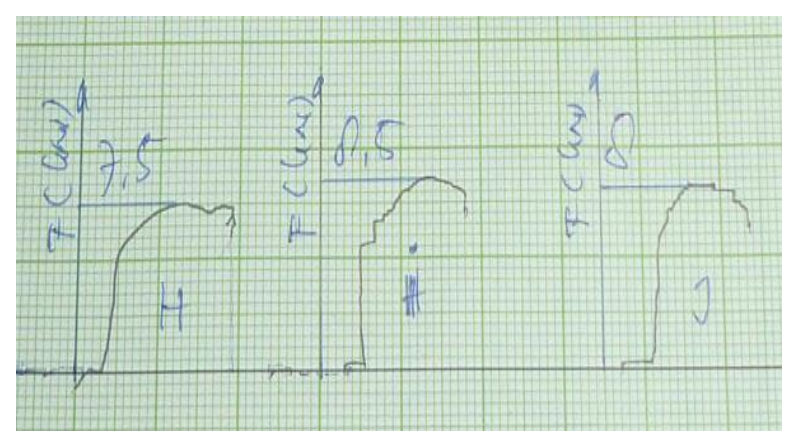

Gambar 4.b. Grafik hasil uji tekuk pada temperature $60^{\circ} \mathrm{C}$, dan waktu electroplating 10 menit, variasi kuat arus H). 4 A, I). 5 A, J). 6 A.

Pada gambar 4.b, memperlihatkan grafik hasil uji tekuk pada kondisi temperatur tetap 60 ${ }^{\circ} \mathrm{C}$, waktu tetap 10 menit, dan variasi kondisi kuat arus, menunjukkan nilai kuat tekuk trent meningkat secara signifikan yaitu dengan $4 \mathrm{~A}$ nilai kekuatan tekuknya adalah $7,5 \mathrm{~kg} / \mathrm{mm}^{2}$, dengan kuat arus listrik $6 \mathrm{~A}$, nilai kekuatan tekuknya turun menjadi $8 \mathrm{~kg} / \mathrm{mm}^{2}$. Dengan perbedaannya sekitar $14 \%$. Hal ini disebabkan karena ada perbedaan kuat arus listrik saat proses pelapisan, dimana kuat arus listrik dapat mempengaruhi ketebalan lapisan yang terbentuk. Dengan ketebalan lapisan yang besar pada sampel akan menambah tahanan dari kekuatan tekuk atau bending saat diuji. Namun pada sampel ini yang tertinggi kekuatan tekuknya pada proses pelapisan waktu celup 10 menit dan kuat arus listriknya $5 \mathrm{~A}$.

\section{Analisis pengujian kekerasan}

Pengujian kekerasan plat sampel dilakukan dengan variasi waktu celup, kuat arus dan temperatur menghasilkan hasil nilai kekerasan yang berbeda-beda dapat dilihat tabel1, dan gambar 5a, dan 5b, di bawah ini.

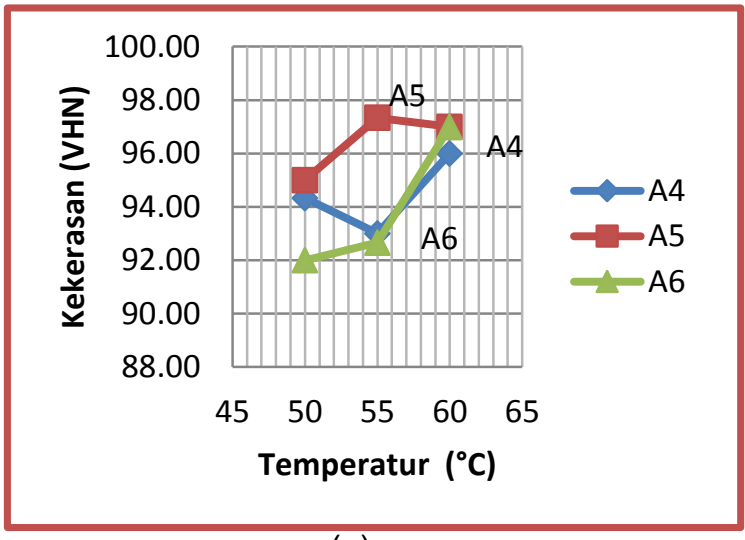

(a)

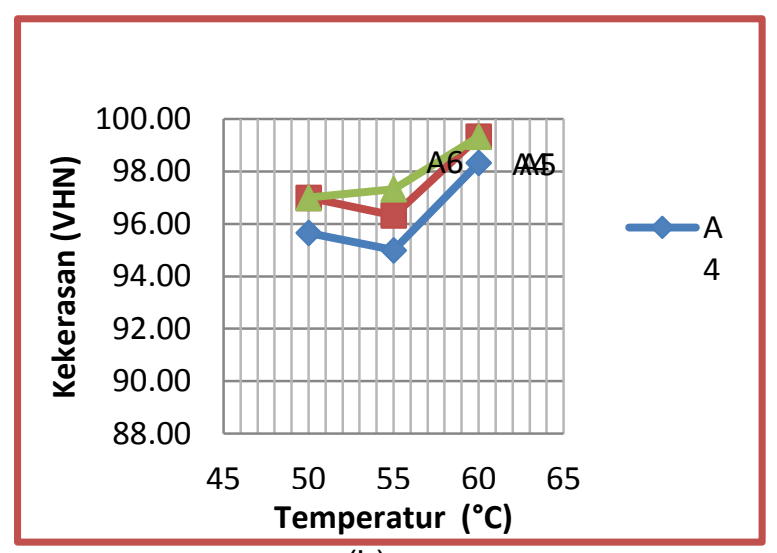

(b)

Gambar 5b. Nilai kekerasan terhadap temperature dengan variasi (a) kuat arus dan (b) waktu.

Tabel 1. Hasil pengujian kekerasan terhadap temperatur dan kuat arus listrik serta waktu celup.

\begin{tabular}{ccrcl}
\hline Waktu & Kuat & \multicolumn{3}{c}{ Temperatur $\left({ }^{\circ} \mathrm{C}\right)$} \\
\cline { 3 - 5 } (Jam) & arus (A) & 50 & 55 & \multicolumn{1}{c}{60} \\
\hline T5 & A4 & 98.33 & 97.66 & 97.33 \\
& A5 & 97.00 & 99.66 & 96.33 \\
& A6 & 89.33 & 95.00 & 100.00 \\
T10 & A4 & 94.33 & 93.00 & 96.00 \\
& A5 & 95.00 & 97.33 & 97.00 \\
& A6 & 92.00 & 92.66 & 97.00 \\
T15 & A4 & 95.66 & 95.00 & 98.33 \\
& A5 & 97.00 & 96.33 & 99.33 \\
& A6 & 97.00 & 97.33 & 99.33
\end{tabular}


Pada Tabel 1, dan Gambar $5 a$ dan 5b, menunjukkan bahwa terjadi peningkatan nilai kekerasan $100 \mathrm{VHN}$ (tertinggi)dengan proses electroplating pada kuat arus $6 \mathrm{~A}$, temperature $60^{\circ} \mathrm{C}$ dan waktu 5 jam . Namun nilai kekerasan terendah 89,33 (VHN) dengan proses electroplating pada kndisi kuat arus $6 \mathrm{~A}$, temperature $50^{\circ} \mathrm{C}$ dan waktu 5 jam.

Kenaikan nilai kekerasan (VHN) disebabkan oleh kenaikan kuat arus yang diberikan pada spesimen, semakin tinggi A yang diberikan maka jumlah muatan yang mengalir dan menempel pada katoda akan semakin banyak dan menyebabkan lapisan yang dihasilkan semakin tebal. Tebal lapisan ini mempengaruhi naiknya nilai kekerasan. Kenaikan kekerasan terjadi karena adanya proses pengendapan ion-ion elektrolit yang lebih cepat, sehingga akan lebih banyak atom hidrogen yang masuk secara interstiti kedalam struktur endapan chromium, hal ini akan menyebabkan terjadinya distorsi kisi dan tegangan dalam lapisan menjadi naik karena gerakan dislokasi terhambat.

\section{KESIMPULAN}

Adapun kesimpulan yang dapat diambil dari hasil pengujian adalah sebagai berikut:

1. Peningkatan waktu dan kuat arus dalam electroplating $\mathrm{Ni}-\mathrm{Cr}$ dapat meningkatkan nilai kekerasan. Kenaikan kekerasan terjadi karena adanya proses pengendapan ion-ion elektrolit yang lebih cepat, sehingga akan lebih banyak atom hidrogen yang masuk secara interstiti kedalam struktur endapan nikel dan khromium, hal ini akan menyebabkan terjadinya distorsi kisi dan tegangan dalam lapisan menjadi naik karena gerakan dislokasi terhambat.

2. Dengan meningkatnya temperatur dalam electroplating $\mathrm{Ni}-\mathrm{Cr}$, nilai kuat tarik bertambah.

3. Pada kondisi temperatur dan waktu yang bervariasi dalam electroplating $\mathrm{Ni}-\mathrm{Cr}$, nilai kuat tekuk meningkat.

\section{DAFTAR PUSTAKA}

[1] Sutrisno, Pengaruh variasi waktu baja karbon rendah terhadap struktur mikro, nilai kekerasan, laju korosi dan nilai keausan spesifik, POLITEKNOSAINS VOL.XII NO.2, September 2013, h.10-19.

[2] Richard Alfonso M. N.,Pengaruh temperatur dan waktu pelapisan nikel pada baja karbon, Skripsi, Jurusan Teknik Mesin, FT, USU, Agustus 2005.

[3] M.Husna Al Hasa, Pengaruh Rapat Arus Listrik dan Waktu Electroplating Terhadap Ketebalan Lapisan Nikel Pada Foil Uranium, Urania, ISSN 0852-4777, Vol. 13 No., 1 Januari 2007: h.1-10

[4] Bambang Santoso dan Martijanti Syamsa, Pengaruh Parameter Proses Pelapisan Nikel Terhadap Ketebalan Lapisan. Tugas Akhir Teknik Mesin, Fakultas Teknik, Universitas Jendral Achmad Yani, Bandung, 2007.

[5] Alian, H., 2010, "Pengaruh Tegangan Pada Proses Electroplating Baja Dengan Pelapis Seng Dan Krom Terhadap Kekerasan Dan Laju Korosi ", ProseddingSeminar Nasional Tahunan Teknik Mesin (SNTTM) Ke-9 Palembang.2010,h.123-131

[6] Raharjo, S., 2010, "Pengaruh Variasi Tegangan Listrik Dan Waktu Proses ElectroplatinTerhadap Ketebalan Serta Kekerasan Lapisan PadaBaja Karbon RendahDengan Krom", Thesis, Universitas Diponegoro Semarang.2010

[7] Basmal, Bayuseno, Sri Nugroho, Pengaruh waktu pelapisan tembaga- nikel pada baja karbon rendah secara elektroplating terhadap nilai ketebalan dan kekasaranRotasi- Vol. 14, No. 2, April 2012: 23 -28

[8] Noor, E.A. and Al-Moubaraki,A.H., Corrosion Behavior of Mild Steel in Hydrochloric Acid Solutions. International Journal of Electrochemical Sciences, Volume 3, Page: $806-818.2008$.

[9] Liping W., Yan Gao., Qunji X., Huiwen L., Tao X.. Microstucture and Tribological properties of electrodeposited Ni-Co alloy deposits. Applied Surface Science, Volume 242,Page : 326-332. 2005

[10] Daniel O., Oghenedoro E., Oluleke O.,Effect of Some Process Variables on Nikel Electroplating of Low Carbon Steel,Leonardo Electronic Journal of 
Practices and Technologies ISSN 15831078, (2011), P.79-94.

[11] Sarmed Abdalrasoul S., Abdalrasoul Salihh MAli Safa N., Study the Effect of Nikel Coating on Fatigue Life of Low Carbon Steel Exposed to Corrosive Environments, Journal of Environment and Earth Science , ISSN 2224-3216. Vol. 3, No.5, (2013), P.121-128. 